Prepared for the U.S. Department of Energy

Under Contract DE-AC05-76RL01830

\title{
Initial Component Testing for a Germanium Array Cryostat
}

\section{An Interim Report for the Radionuclide Laboratories Project}

$\begin{array}{ll}\text { ME Keillor } & \text { CE Aalseth } \\ \text { AR Day } & \text { JE Fast } \\ \text { EW Hoppe } & \text { BJ Hyronimus } \\ \text { TW Hossbach } & \text { A Seifert }\end{array}$

June 2009

\section{Pacific Northwest}

NATIONAL LABORATORY

Proudly Operated by Battelle Since 1965 


\title{
DISCLAIMER
}

This report was prepared as an account of work sponsored by an agency of the United States Government. Neither the United States Government nor any agency thereof, nor Battelle Memorial Institute, nor any of their employees, makes any warranty, express or implied, or assumes any legal liability or responsibility for the accuracy, completeness, or usefulness of any information, apparatus, product, or process disclosed, or represents that its use would not infringe privately owned rights. Reference herein to any specific commercial product, process, or service by trade name, trademark, manufacturer, or otherwise does not necessarily constitute or imply its endorsement, recommendation, or favoring by the United States Government or any agency thereof, or Battelle Memorial Institute. The views and opinions of authors expressed herein do not necessarily state or reflect those of the United States Government or any agency thereof.

\author{
PACIFIC NORTHWEST NATIONAL LABORATORY \\ operated by \\ BATTELLE \\ for the \\ UNITED STATES DEPARTMENT OF ENERGY \\ under Contract DE-AC05-76RL01830
}

Printed in the United States of America
Available to DOE and DOE contractors from the Office of Scientific and Technical Information,
P.O. Box 62, Oak Ridge, TN 37831-0062;
ph: (865) 576-8401
fax: $(865)$ 576-5728
email: reports@adonis.osti.gov

\begin{abstract}
Available to the public from the National Technical Information Service, U.S. Department of Commerce, 5285 Port Royal Rd., Springfield, VA 22161 ph: (800) 553-6847 fax: $(703) 605-6900$ email: orders@ntis.fedworld.gov online ordering: http://www.ntis.gov/ordering.htm
\end{abstract}

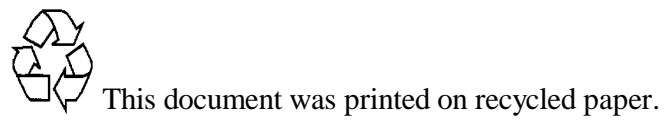




\section{Initial Component Testing for a Germanium Array Cryostat}

\section{An Interim Report for the Radionuclide Laboratories Project}

$\begin{array}{ll}\text { ME Keillor } & \text { CE Aalseth } \\ \text { AR Day } & \text { JE Fast } \\ \text { EW Hoppe } & \text { BJ Hyronimus } \\ \text { TW Hossbach } & \text { A Seifert }\end{array}$

June 2009

Prepared for

the U.S. Department of Energy

under Contract DE-AC05-76RL01830

Pacific Northwest National Laboratory

Richland, Washington 99352 


\section{Summary}

This report describes progress on the construction of two ultra-low-background cryostats that are part of the NA-22 funded "Radionuclide Laboratories" (RN Labs) project. Each cryostat will house seven high-purity germanium crystals (HPGe). These cryostats are being built from a limited set of materials that are known to have very low levels of radioactive impurities. The RN Labs instrument is designed to take advantage of low background performance, high detection efficiency, and $\gamma-\gamma$ coincidence signatures to provide unprecedented gamma spectroscopy sensitivity. The project is focused on improving gamma analysis capabilities for nuclear detonation detection (NDD) applications. The instrument also has the potential for basic nuclear physics research.

Section 1 provides the background for the project. Section 2 discusses germanium crystal acceptance testing. Design problems were found after the first delivery of new detectors from the vendor, Canberra Semiconductors. The first four crystals were returned for repair, resulting in a delay in crystal procurement. Section 3 provides an update on copper electroforming. In general, electroforming parts for RN Labs has proceeded smoothly, but there have been recent problems in electroforming three large copper parts necessary for the project. Section 4 describes the first round of testing for the instrument: anti-cosmic scintillator testing, electronics testing, and initial vacuum testing. Section 5 concludes with an overall description of the state of the project and challenges that remain. 


\section{Acronyms and Abbreviations}

$\begin{array}{ll}\text { EBSD } & \text { electron backscatter diffraction } \\ \text { HPGe } & \text { high-purity germanium } \\ \text { HV } & \text { high voltage } \\ \text { IR } & \text { infrared radiation } \\ \text { LA-ICP-MS } & \text { laser ablation inductively coupled plasma mass spectrometry } \\ \text { MWPC } & \text { multi-wire proportional counter } \\ \text { NDD } & \text { Nuclear Detonation Detection } \\ \text { PGT } & \text { Princeton Gamma Tech } \\ \text { PNNL } & \text { Pacific Northwest National Laboratory } \\ \text { RN Labs } & \text { Radionuclide Laboratories (project) } \\ \text { SEM } & \text { scanning electron microscopy } \\ \text { SIMS } & \text { secondary ionization mass spectrometry }\end{array}$




\section{Contents}

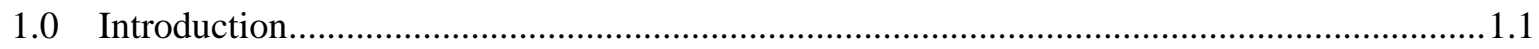

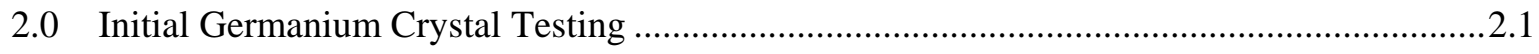

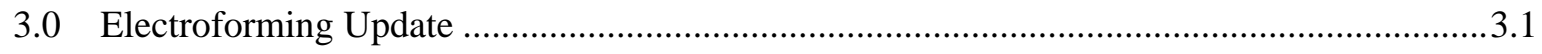

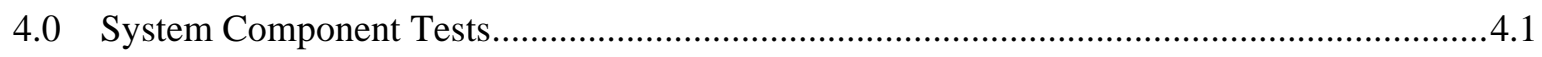

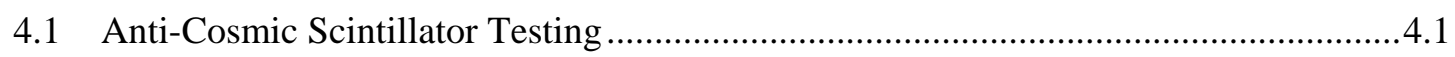

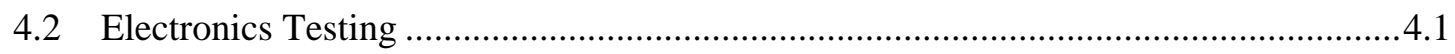

4.3 Initial Vacuum Testing of Cryostat \#1 .................................................................... 4.2

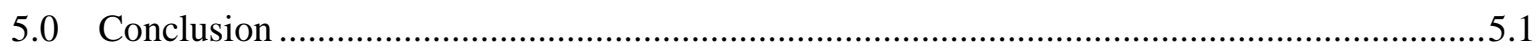

\section{Figures}

2.1. I-V Curve for One of the HPGe Crystals Refurbished by PGT ........................................... 2.1

2.2. HPGe Crystal Received from Canberra ............................................................................. 2.2

2.3. This Image of the Canberra Cryostat Shows Part of the "Pogo Pin" Central Contact Rod ......... 2.3

3.1. Completed Cryostat Parts for First Cryostat of RN Labs Instrument ..................................... 3.1

3.2. Large Electroformed Parts that Have Suffered Nucleation Issues, Resulting in Numerous

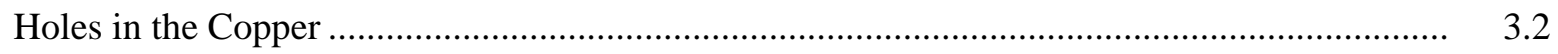

3.3. SEM Image Showing Transition of the Copper Grain Structure ............................................ 3.3

3.4. SEM Image Showing Large, Oriented Grain Structure …......................................................

3.5. Alternative Plating Geometry for Entrance Window............................................................. 3.4

4.1. Muon Peak in Plastic Anti-Cosmic Detector .............................................................................

4.2. Initial Vacuum Testing of the First RN Labs Cryostat ........................................................ 4.2

4.3. HV Feedthrough Pins Accidentally Bent when the Service Body Was Placed with this Side Down. 


\subsection{Introduction}

Two ultra-low-background cryostats are currently under construction for the NA-22 funded "Radionuclide Laboratories" (RN Labs) project. Each cryostat will house seven high-purity germanium crystals (HPGe). We are building these cryostats from a limited set of materials that are known to have very low levels of radioactive impurities. The vast majority of each cryostat is made from pure copper electroformed into near-final geometry at Pacific Northwest National Laboratory (PNNL) under class 1000 clean room conditions.

The RN Labs instrument is designed to take advantage of low background performance, high detection efficiency, and $\gamma-\gamma$ coincidence signatures to provide unprecedented gamma spectroscopy sensitivity. The project is focused on improving gamma analysis capabilities for Nuclear Detonation Detection (NDD) applications, e.g., nuclear treaty monitoring. The instrument also has the potential for basic nuclear physics research. For example, we currently have a graduate student working on the potential for this detector to measure the half-life of predicted rare decay modes of ${ }^{130} \mathrm{Te}$. We also have an undergraduate student building a multi-wire proportional counter (MWPC) active anti-cosmic detector. An active anti-cosmic system is a crucial component to allow the instrument to achieve high sensitivities for NDD measurements.

This report details the acceptance testing of HPGe crystals refurbished by Princeton Gamma Tech (PGT) and crystals purchased new from Canberra Semiconductor. It also provides an update on the current status of copper electroforming. The results of initial tests with plastic scintillator anti-cosmic detectors are briefly discussed, as are the design and testing of analogue signal processing electronics. Finally, results of the first round of vacuum testing for the first cryostat are covered. 


\subsection{Initial Germanium Crystal Testing}

HPGe crystals were obtained from both PGT and Canberra Semiconductor for use in the RN Labs instrument. The crystals are nominally 63-mm-diameter and 70-mm-height semi-coaxial P-type detectors with a guard "ditch" surrounding the central bore hole. The fragile contact is protected by gold plating at the entrance of the bore hole.

Eight HPGe crystals available from the completed NA-22 MEGA project were available for use on the RN Labs research. A contract was arranged with PGT to refurbish these eight crystals. All eight of these crystals have been received, tested, and removed from the shipping cryostats. The agreement with PGT did not include an energy-resolution specification for these refurbished crystals, so acceptance was based on the results of an I-V curve measurement. Figure 2.1 is an example of a typical I-V curve for these PGT crystals. The crystals were stored in a nitrogen dry box for various periods of time (up to $\sim 1$ year) after initial testing and then moved to vacuum storage. The crystals are currently in vacuum storage awaiting installation in one of the RN Labs cryostats.

\section{RN LABS Crystal 3057}

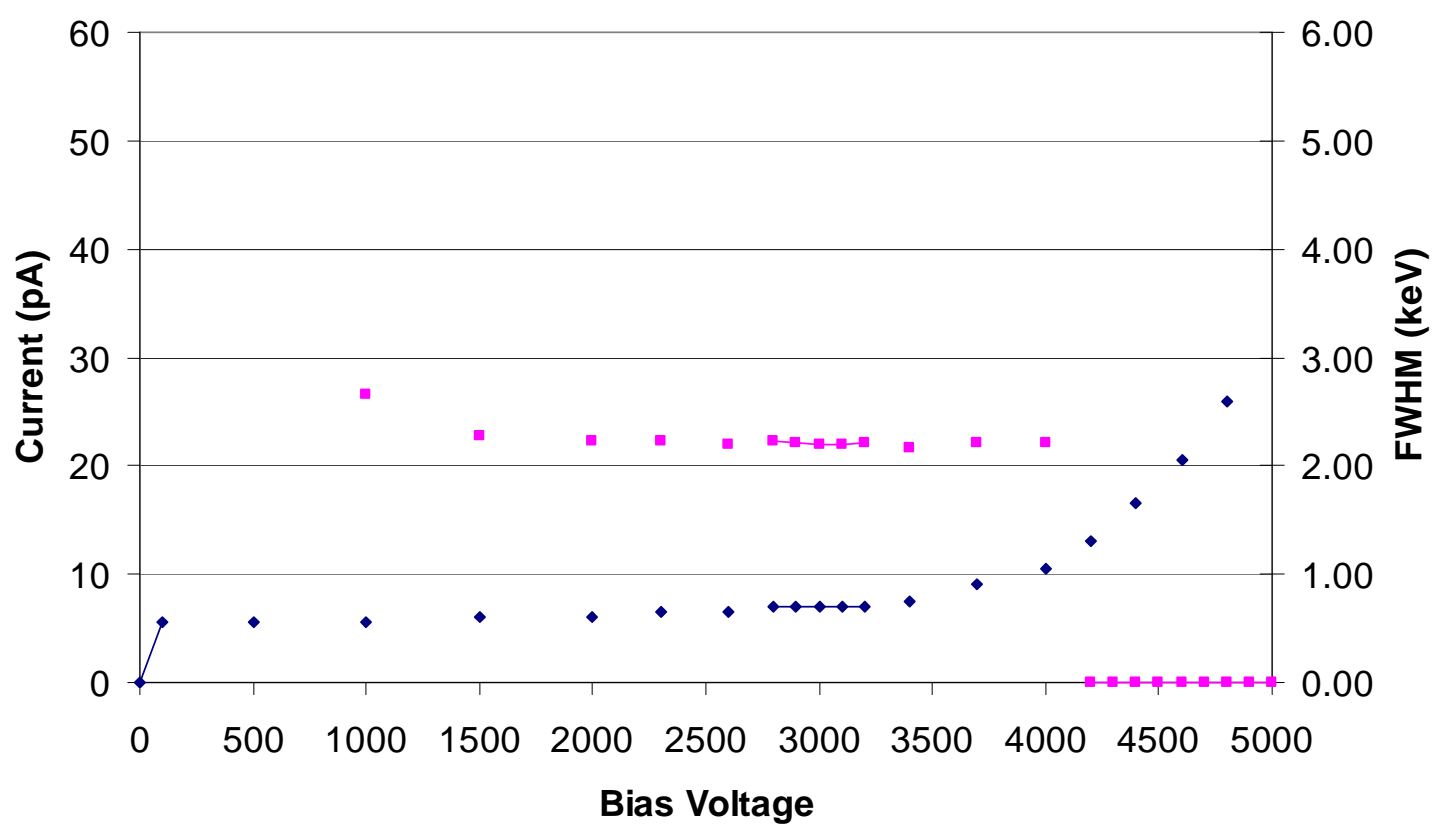

Figure 2.1. I-V Curve for One of the HPGe Crystals Refurbished by PGT. Energy resolution at 1332 $\mathrm{keV}$ is also plotted.

An initial shipment of four new crystals from Canberra Semiconductor was tested against factory specifications. After testing, the first of these crystals was removed from its shipping cryostat. Upon removal, we noted that 1 ) excessive amounts of indium were used on the crystal (inconsistent with a low 
background detector-see Figure 2.3) and 2) the "pogo pin" style of signal contact was used (see Figure 2.3). This latter point made the crystals unsuitable for use in RN Labs, both due to indium at the bottom of the central bore hole and the lack of protective gold plating at the entrance to the bore hole. These features were not consistent with the order specifications, so all four detectors were returned to Canberra for repair. This issue substantially delayed the receipt of the final eight crystals. We have recently received five Canberra detectors that are now in acceptance testing, and we are awaiting the final three crystals.

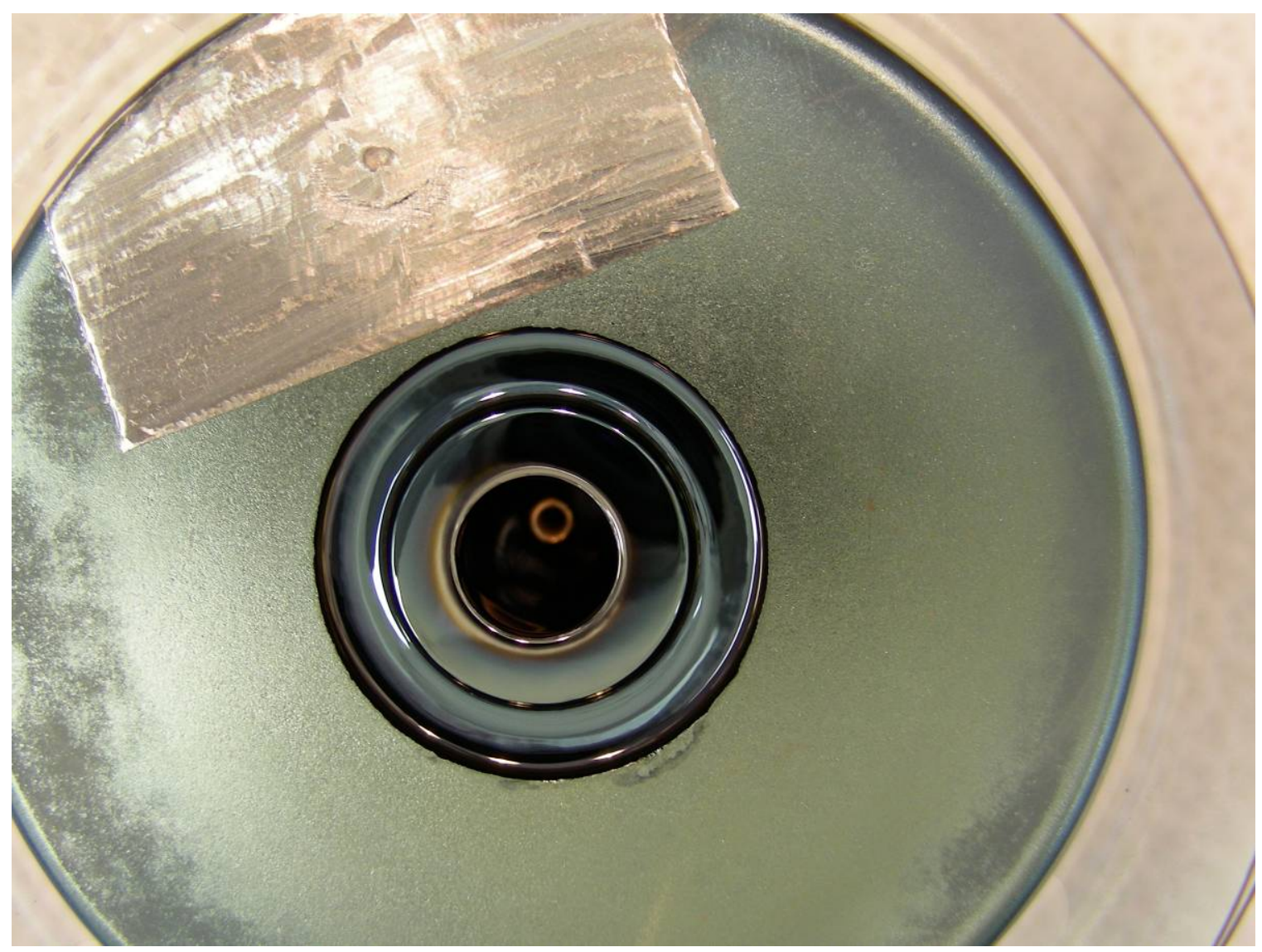

Figure 2.2. HPGe Crystal Received from Canberra. The large indium patch is the silver colored material at the top of the image. The end of the "pogo pin" contact rod is visible inside the bore hole, and the visible end of the bore hole is not plated with gold. 


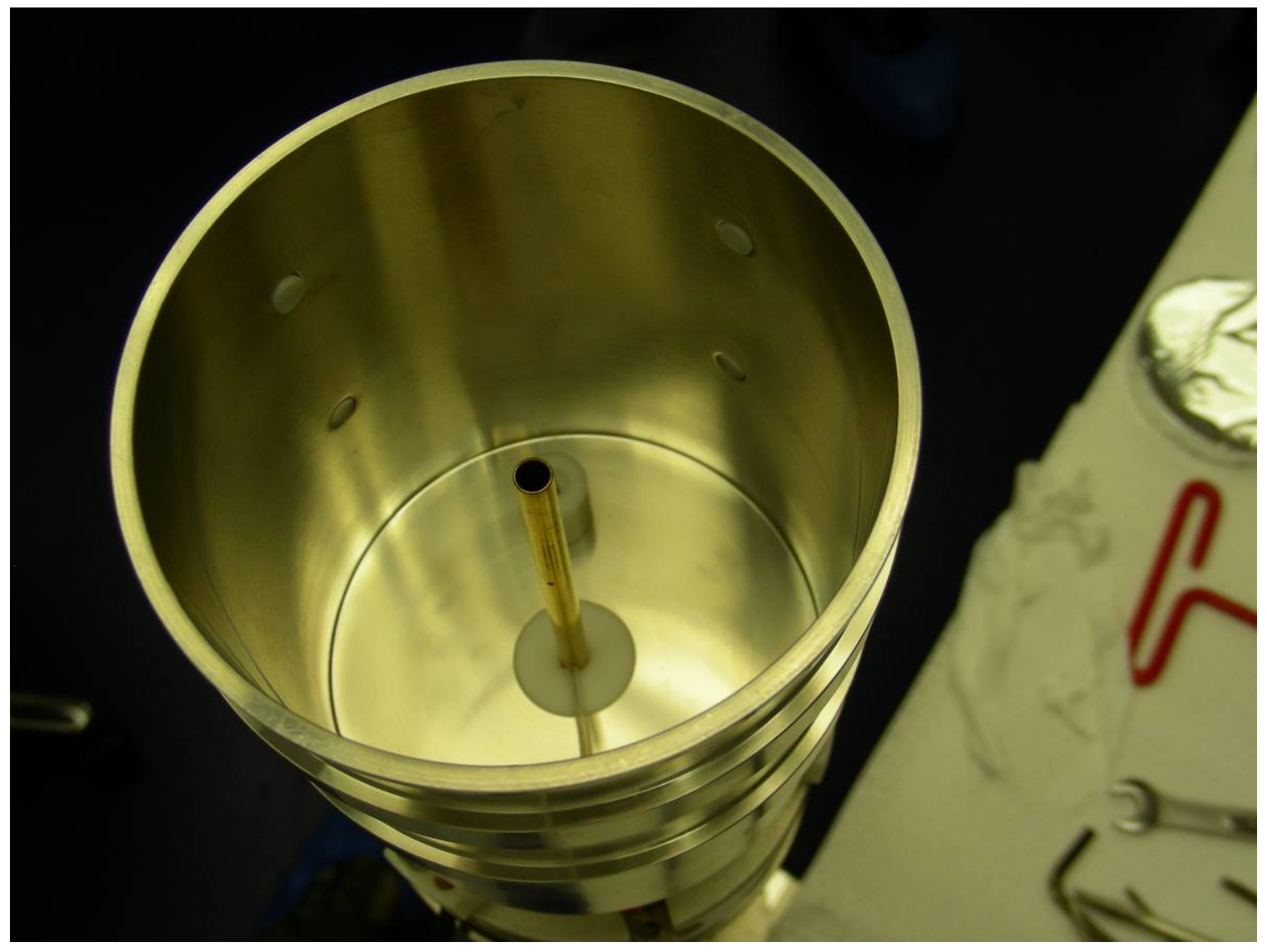

Figure 2.3. This Image of the Canberra Cryostat Shows Part of the "Pogo Pin" Central Contact Rod 


\subsection{Electroforming Update}

In general, electroforming parts for RN Labs has proceeded smoothly, and the vast majority of parts have been successfully completed. Figure 3.1 shows nearly all of the copper parts required for the first cryostat, along with the electroformed cross arm and cold finger for the second cryostat (still on mandrels in this image).

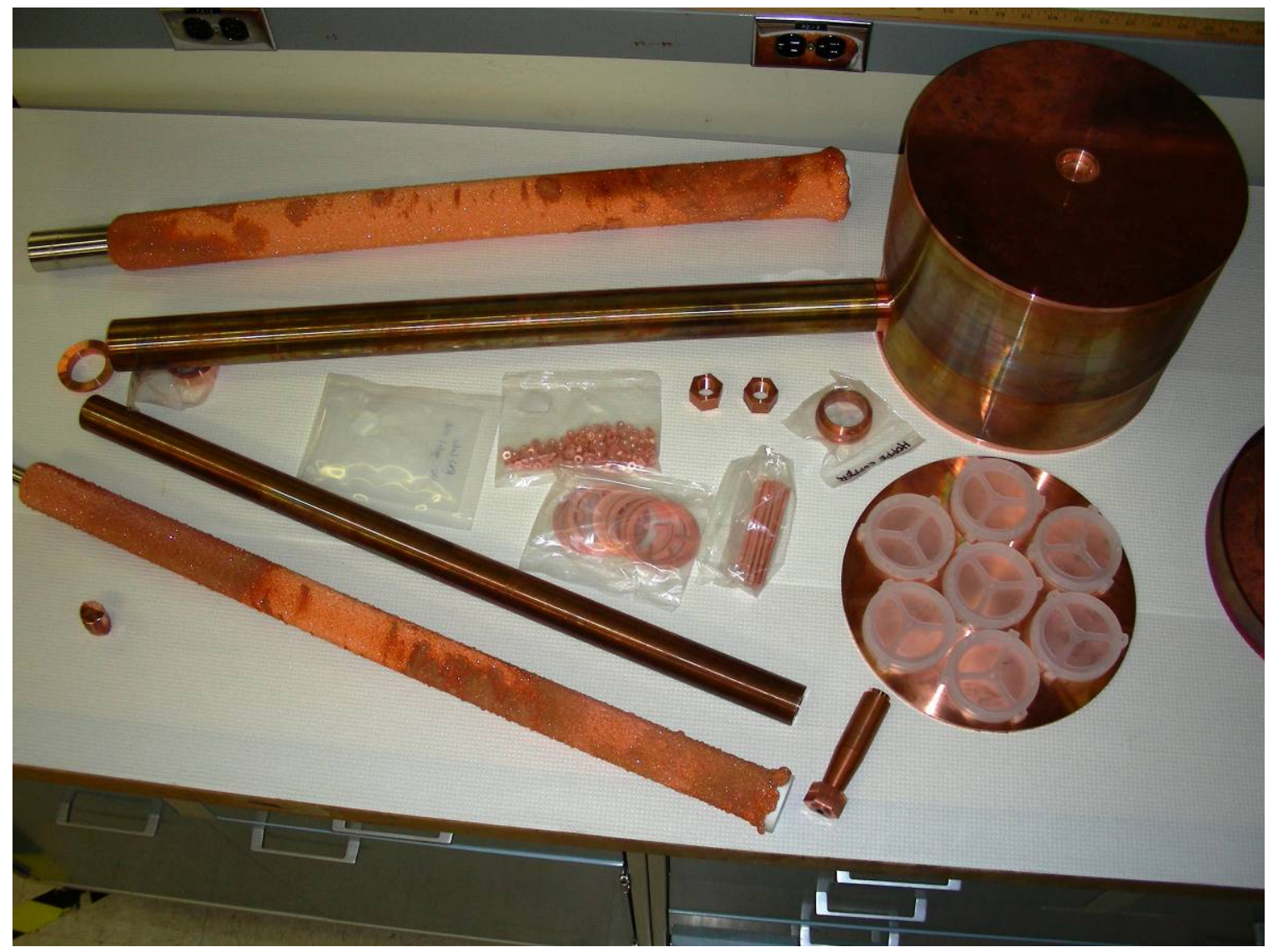

Figure 3.1. Completed Cryostat Parts for First Cryostat of RN Labs Instrument

Unfortunately, we have experienced difficulty in electroforming three specific large copper parts necessary for the project. The affected parts are the infrared radiation (IR) shields and the domed entrance window. The IR shields are very thin parts that take a matter of a few days to electroform, so we anticipate that there is sufficient time to resolve the issues discussed below and complete these parts. The entrance window is a much more challenging part, both due to its geometry and its thickness. This part will take $\sim 2$ to 3 months to electroform so that completing the thin entrance window within FY09 depends upon rapid resolution of poor copper nucleation and adhesion issues, or upon developing an alternative solution. 
Obtaining proper copper nucleation and adhesion to the stainless steel mandrels is essential to proper growth of the part. Figure 3.2 displays two separate attempts to electroform an entrance window and an attempt at one of the IR shields. These parts all suffered from poor nucleation so that the resulting copper had significant holes. Holes are not acceptable for either the entrance window (which must hold vacuum) or the IR shields (which must prevent infrared radiation from striking the HPGe crystals). We are in the process of determining the source of these issues.
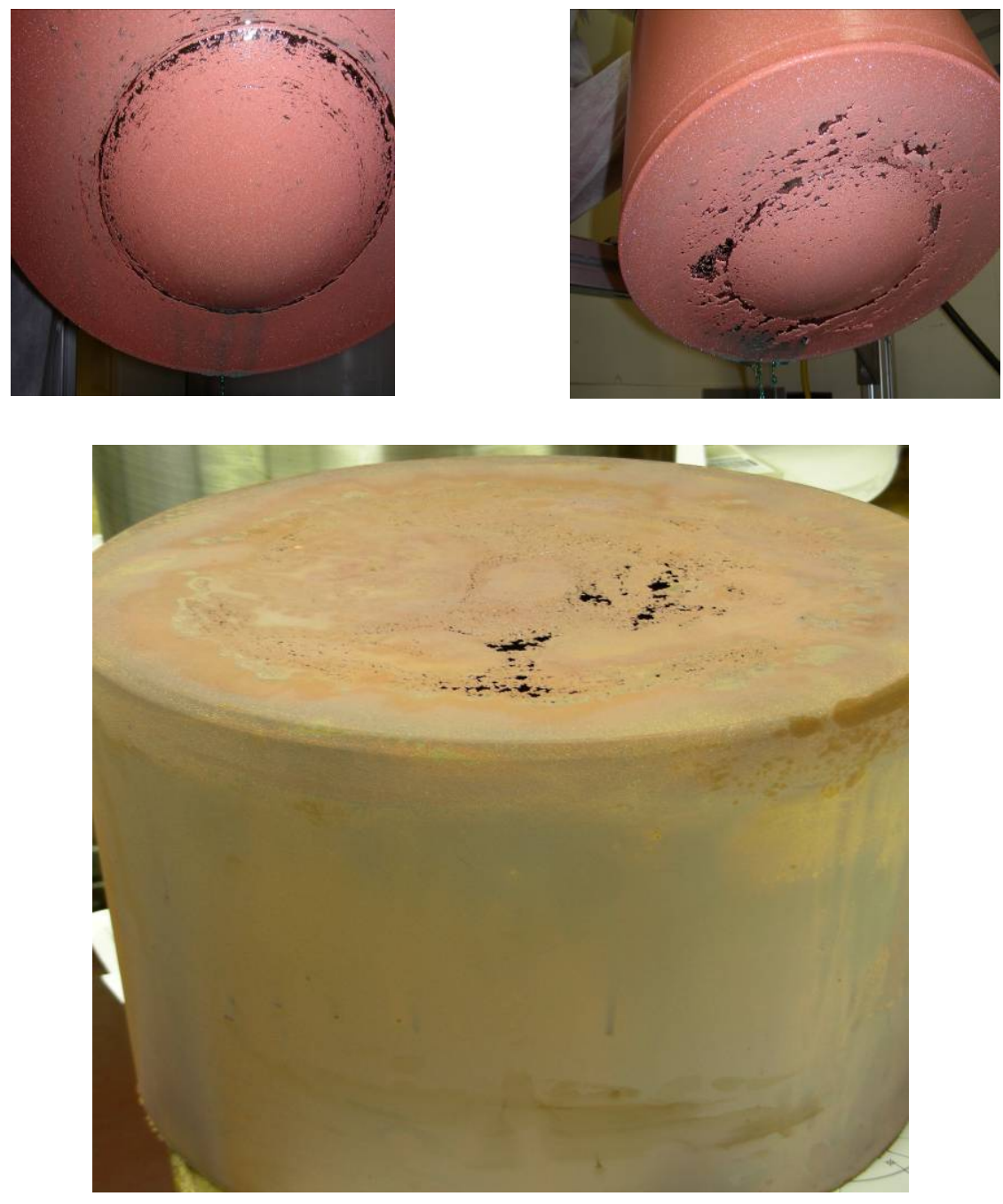

Figure 3.2. Copper Nucleation Problems. Large electroformed parts that have suffered nucleation issues, resulting in numerous holes in the copper

Additives employed in typical electrochemical manufacturing processes aid in the development of nucleation. However, to obtain the greatest purity copper possible, we do not use additives since it has been established that these materials and even inert particles such as alumina can be incorporated in the growing copper matrix during electrodeposition.

To determine the nucleation and growth mechanisms at play under the electrodeposition conditions used, various copper samples were analyzed via scanning electron microscopy (SEM) with electron 
backscatter diffraction (EBSD) to determine their microstructure, including grain size and orientation. Secondary ionization mass spectrometry (SIMS) and laser ablation inductively coupled plasma mass spectrometry (LA-ICP-MS) were also performed to determine relative surface concentrations of impurities and to map impurity localization on the copper surface.

For SEM and SIMS analysis, samples were mounted in epoxy for metallographic polishing and given a series of successively finer-grit mechanical polishing steps using diamond grits with a final polish of colloidal silica. For LA-ICP-MS, electroplated copper samples were etched in $3 \% \mathrm{H}_{2} \mathrm{O}_{2} / 1 \% \mathrm{H}_{2} \mathrm{SO}_{4}$.

All of the samples showed a very fine grain size at the interior surface directly in contact with the mandrel (see Figure 3.3). After a few hundred microns, this tended to transition to a larger elongated grain structure that often had a strong texture. For some samples, the texture continued to refine itself out to the edge of the sample, producing very large, highly oriented grains (see Figure 3.4).
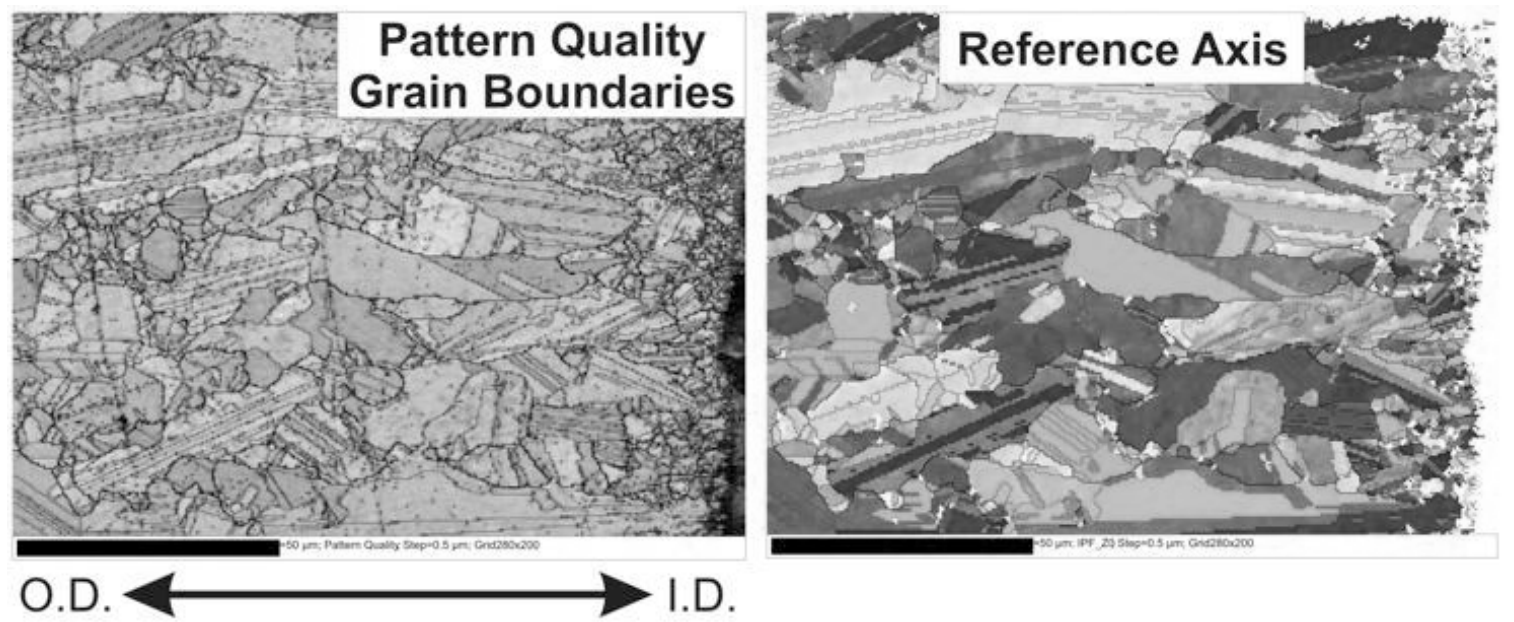

Figure 3.3. SEM Image Showing Transition of the Copper Grain Structure
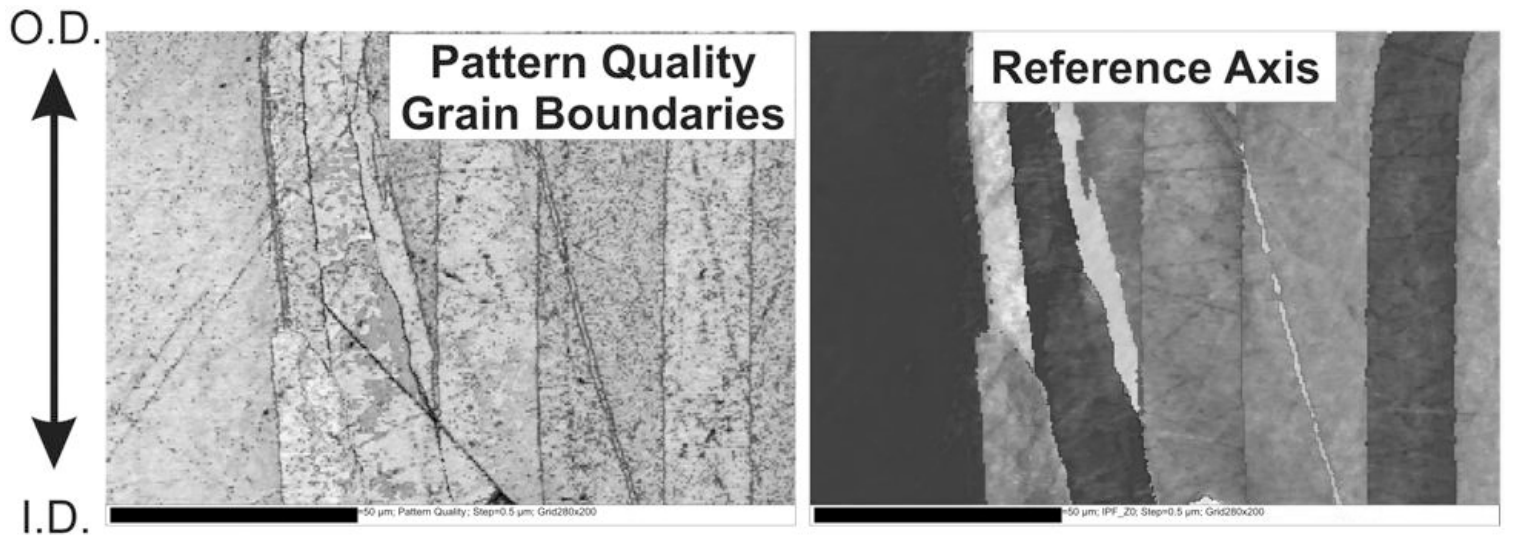

Figure 3.4. SEM Image Showing Large, Oriented Grain Structure

These data provide evidence for instantaneous nucleation and highly selective grain growth during the electrodeposition process, though further work needs to be done to distinguish between nucleation and growth patterns and the effects of self-annealing or recrystallization. 
The solution to the difficulties encountered in electroplating these large parts is to provide more controlled surface conditions that favor uniform nucleation on the stainless steel mandrels.

Electropolishing, an electrochemical cleaning process, is being aggressively investigated to resolve the problem. Chemical etching is another possible solution that is also being tested.

We are also investigating alternative plating geometries that would be quicker to produce. Figure 3.5 shows an alternative entrance window geometry that would allow plating of the entrance window separate from the thicker plate surrounding the window. In this geometry, the window would be electroformed as a 6 " diameter part, then e-beam welded into the heavier plate. We are pursuing this alternative in parallel with plating the part as a single unit.
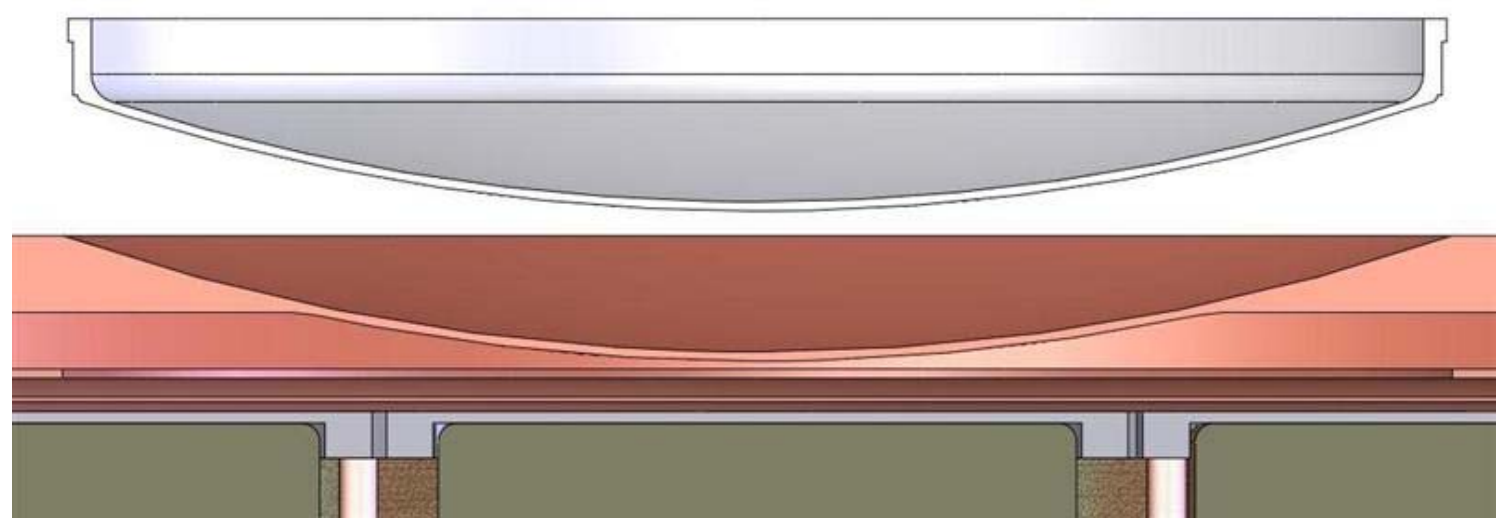

Figure 3.5. Alternative Plating Geometry for Entrance Window. The upper part of the figure shows an entrance window plated on a 6 inch mandrel. This window would then be e-beam welded into the annular plate. This geometry is less likely to suffer from the nucleation issues we have experienced with the larger 11 inch mandrel. 


\subsection{System Component Tests}

This section discusses the following completed or in-progress tests: anti-cosmic scintillator testing, electronics testing, and initial vacuum testing of Cryostat \#1.

\subsection{Anti-Cosmic Scintillator Testing}

An important part of the overall background performance of the RN Labs instrument is suppression of cosmic-ray backgrounds. Tests have been performed with plastic scintillator cosmic-ray detectors, and a design for an effective active cosmic-ray veto system for RN Labs has been prepared. The results of these initial laboratory tests indicate that 2-inch-thick scintillating plastic panels will provide good cosmic-ray identification while remaining relatively insensitive to external gamma-ray backgrounds. Based on the results of these tests, an active anti-cosmic shield system has been designed, and we are currently awaiting bids from suppliers.

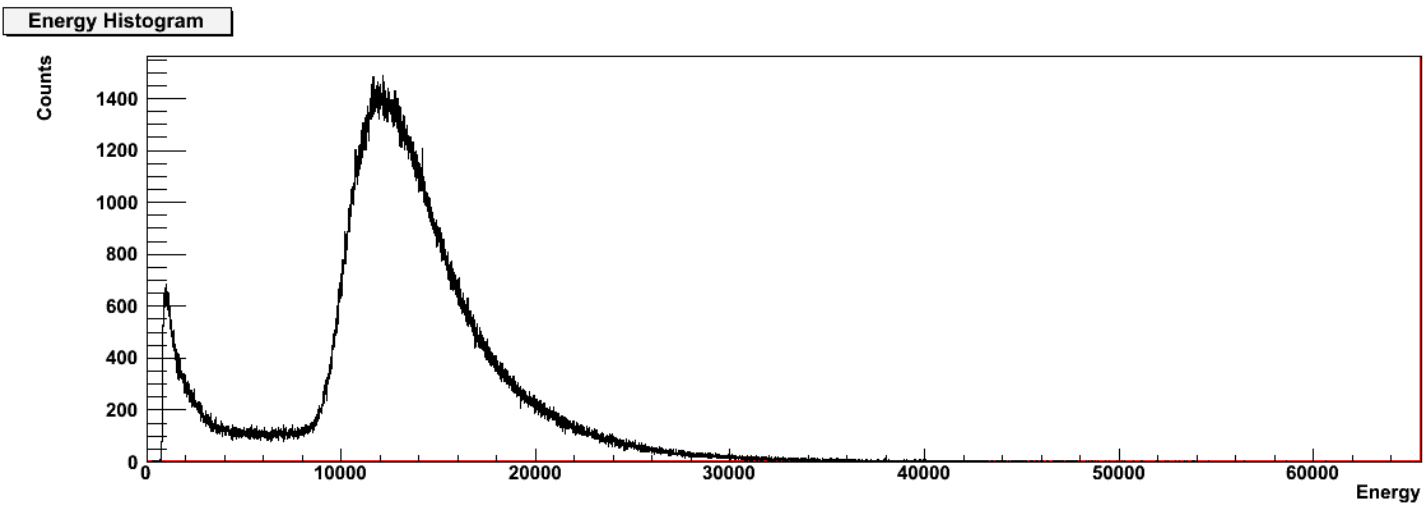

Figure 4.1. Muon Peak in Plastic Anti-Cosmic Detector. This figure shows the muon through-peak in a 2 inch thick plastic scintillator. This spectrum is from "tagged" muons, in other words events observed in two independent scintillators at the same time. Energy is in ADC channel units. The rising continuum at the low energy end is caused by detection of gamma-rays; we anticipate good separation between gamma-rays and muons, as displayed in this spectrum.

\subsection{Electronics Testing}

Another critical part of the RN Labs instrument is the amplification and analog signal path for the very small electrical signals that are produced in the HPGe crystals as a result of radiation interactions. A sensitive front-end amplifier made with radiopure materials has been designed and tested, along with a low-background signal cable design. Final production of the front-end amplifiers for RN Labs has not been completed, but 16 research prototypes have been prepared to support initial instrument testing. These custom PNNL components will be combined with a semi-custom commercial preamplifier (BridgePort Instruments) for the final signal conditioning before output signals are digitized for further analysis. Tests with the first revision of the semi-custom preamplifiers are now complete, and several small design revisions were identified to provide better (lower) noise performance. Revised prototypes are expected to be available on time for integration into the RN Labs instrument. A parallel research path 
using commercial off-the-shelf preamplifiers has also been pursued to reduce project risk and has proven to provide the necessary performance for RN Labs should the revised semi-custom solution not meet expectations.

\subsection{Initial Vacuum Testing of Cryostat \#1}

The vacuum boundary of cryostat \#1 has been assembled for vacuum testing. This assembly includes the main body of the cryostat, the cross arm, and the service body (see Figure 4.2).

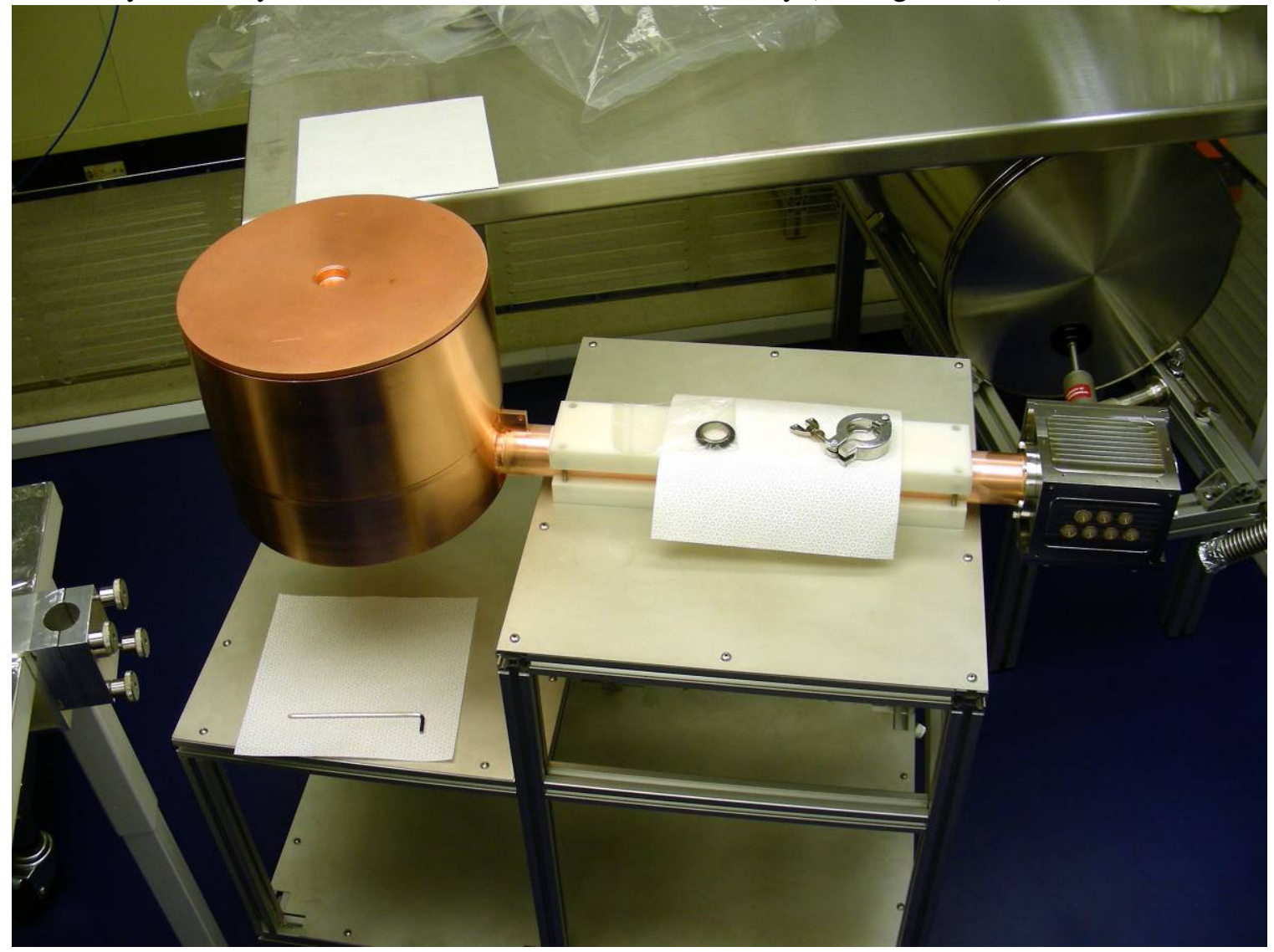

Figure 4.2. Initial Vacuum Testing of the first RN Labs Cryostat. The top plate in this image is a test piece; production of a large, thin entrance window for the cryostat is one of the more challenging aspects of the cryostat production.

The main body of the cryostat, in this test configuration, requires three seals around the circumference of the chamber. Each seal is $~ 36$ inches long. In the final configuration of the cryostat, the plate containing the entrance window will be e-beam welded to the corresponding cylinder, eliminating one of these three seals. Several smaller seals are located on the service body, including the cross arm-to-service body connection, the pump out port plate, a blank plate, and the service body-to-Dewar connection. The vacuum integrity of welds was tested: e-beam welds on each end of the cross arm, welds on the service body, and a laser weld test for the 50-pin feed-through on the service body. Thunderline $\mathrm{Z}$ high-voltage feedthroughs were cemented into the service body with Torr Seal, and these seals were also checked for vacuum leaks. 
During the initial leak testing, we have been unable (thus far) to achieve the seal for the bottom plate. It appears that the "hoop" warped slightly during e-beam welds of the cross arm and cross arm gussets. The integrity of the other two large seals on the main body of the cryostat cannot be verified until the lower seal is corrected. A detailed plan has been developed to resolve this issue, and is currently in progress.

To proceed with leak testing, a blank plate and o-ring were used to seal the end of the cross arm inside of the main chamber. This allowed us to leak check the cross arm and service body. No response to helium was observed at any of the welds, nor at any of the o-ring seals on the service body. Leaks were observed at three of the high voltage (HV) feedthroughs. These three feedthroughs were accidentally bent when the service body was assembled (see Figure 4.3); the service body was turned onto the side containing the HV feedthroughs, bending three pins. These three pins were subsequently straightened; however, it is now apparent that the seals between the pins and ceramic insulators were compromised. These feedthroughs will be replaced. We are also fabricating a temporary cover to prevent recurrence of damaged HV feedthroughs.

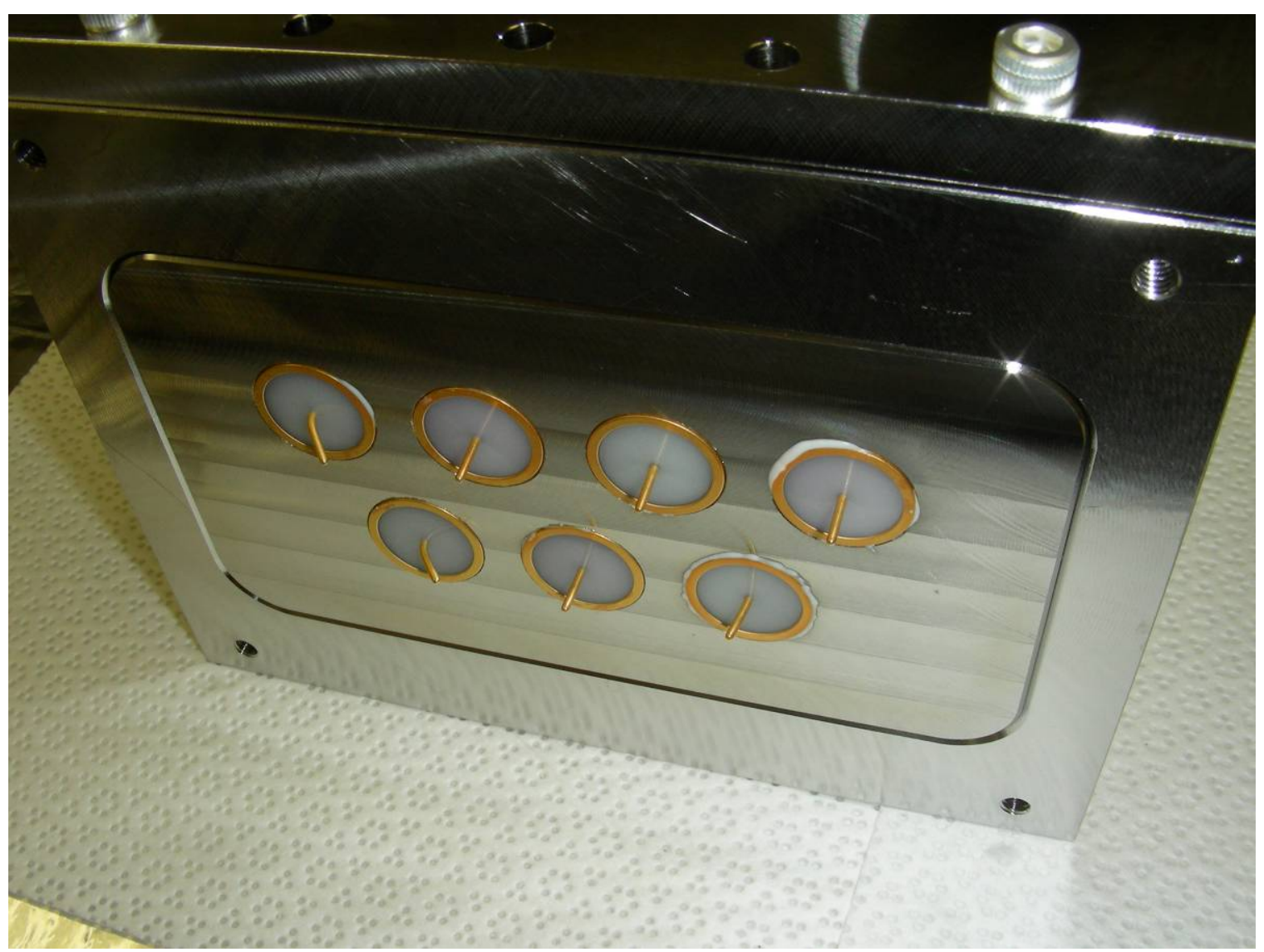

Figure 4.3. HV Feedthrough Pins. Three pins were accidentally bent when the service body was placed with this side down. Leak testing has shown that the vacuum integrity of these feedthroughs was compromised, and they will be replaced. A temporary cover is being fabricated to prevent similar damage in the future. 


\subsection{Conclusion}

We are currently progressing rapidly toward construction of the first RN Labs seven crystal array. We anticipate resolving the current vacuum seal issue with the cryostat in short order; we will then complete some quick thermal tests of the Dewar-cold finger-cold plate combination and proceed with assembling the first half of the array.

Unanticipated challenges with electroforming have delayed the schedule for production of three of the electroformed parts. We expect to resolve these problems with plenty of time to complete the IR shields for the system. The delays are more problematic for the entrance window because of the long period of time required for it to be electroformed. We are exploring alternatives for this part, and the existing oxygen-free high-conductivity copper test piece will allow us to proceed with assembly and testing of the first array. 